\title{
Sub-band-gap laser micromachining of lithium niobate
}

\author{
Christensen, F. K.; Müllenborn, Matthias
}

Published in:

Applied Physics Letters

Link to article, DOI:

$10.1063 / 1.113470$

Publication date:

1995

Document Version

Publisher's PDF, also known as Version of record

Link back to DTU Orbit

Citation (APA):

Christensen, F. K., \& Müllenborn, M. (1995). Sub-band-gap laser micromachining of lithium niobate. Applied Physics Letters, 66(21), 2772-2773. https://doi.org/10.1063/1.113470

\section{General rights}

Copyright and moral rights for the publications made accessible in the public portal are retained by the authors and/or other copyright owners and it is a condition of accessing publications that users recognise and abide by the legal requirements associated with these rights.

- Users may download and print one copy of any publication from the public portal for the purpose of private study or research.

- You may not further distribute the material or use it for any profit-making activity or commercial gain

- You may freely distribute the URL identifying the publication in the public portal

If you believe that this document breaches copyright please contact us providing details, and we will remove access to the work immediately and investigate your claim. 


\title{
Sub-band-gap laser micromachining of lithium niobate
}

\author{
F. K. Christensen ${ }^{\text {a) }}$ \\ Ferroperm Components A/S, DK-3000 Helsingdr, Denmark \\ M. Müllenborn \\ Mikroelektronik Centret, Danmarks Tekniske Universitet, DK-2800 Lyngby, Denmark
}

(Received 6 February 1995; accepted for publication 20 March 1995)

\begin{abstract}
Laser processing of insulators and semiconductors is usually realized using photon energies exceeding the band-gap energy. This makes laser processing of insulators difficult since high photon energies typically require either a pulsed laser or a frequency-doubled continuous-wave laser. A new method is reported which enables us to do laser processing of lithium niobate using sub-band-gap photons. Using high scan speeds, moderate power densities, and sub-band-gap photon energies results in volume removal rates in excess of $10^{6} \mu \mathrm{m}^{3} / \mathrm{s}$. This enables fast micromachining of small piezoelectric structures, or simple etching of grooves for precision positioning of optical fibers. (C) 1995 American Institute of Physics.
\end{abstract}

Lithium niobate is used in many different applications ranging from surface acoustic wave devices, e.g., bandpass filters, to photonic devices such as optical waveguides and holograms. A major problem in manufacturing lithiumniobate-based devices is its well-known resistivity towards standard machining techniques like wet etching or reactive ion etching. ${ }^{1}$ As a consequence, a number of laser ablation and laser etching experiments has been reported since the mid-eighties ${ }^{2-4}$ all utilizing photon energies above the band gap to ensure sufficient power absorption in the substrate.

Lithium niobate has a band gap of about $3.75 \mathrm{eV}$ at room temperature. At present, pulsed excimer lasers (e.g., $\mathrm{KrF}$ at $5.00 \mathrm{eV}$ ) or frequency-doubled (fd) continuous-wave (cw) lasers (e.g., Ar ion at $4.82 \mathrm{eV}$ ) are the most powerful lasers available for laser processing above the band gap of lithium niobate. A comparison of the removal rates achievable with ablation and etching processes based on these lasers can be found in Ref. 5. The maximum etch rates quoted in Ref. 5 are $\sim 1 \mu \mathrm{m}^{3} / \mathrm{s}$ for the $\mathrm{cw}$ laser process and $0.05 \mu \mathrm{m} /$ pulse $(10 \mathrm{~Hz})$ for the excimer laser process. The volumetric removal rate of the excimer laser depends on the size of the actual structure wanted.

In this letter, we show the results of a new laser processing technique using a cw Ar-ion laser in a direct-write setup. The process is mainly a reduction process utilizing a subband-gap photon energy of $3.53 \mathrm{eV}$, thereby enabling selective removal of the laser-processed substrate by subsequent wet etching. Combining a scan speed of $100 \mathrm{~mm} / \mathrm{s}$, a laser spot of $2 \omega=8 \mu \mathrm{m}$, and $750 \mathrm{~mW}$ of laser power results in corresponding volumetric removal rates in excess of $10^{6} \mu \mathrm{m}^{3} / \mathrm{s}$.

The experimental setup consists of a cw Ar-ion laser with a maximum power of $2.5 \mathrm{~W}$ at $351 \mathrm{~nm}$, UV optics, and a stainless-steel process chamber with a quartz window mounted on a dc motor stage. The powers quoted in this letter are powers at the laser, and the optical loss in our setup is $\sim 50 \%$ at $351 \mathrm{~nm}$. The samples investigated were commercially available $0.5 \mathrm{~mm}$ thick $128^{\circ}$-rotated $Y$-cut lithium nio-

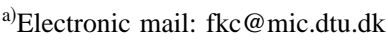

bate, and the process gas used was 5 mbar of $\mathrm{N}_{2}$. After laser processing, the samples were characterized by scanning electron microscopy (SEM), and secondary ion mass spectroscopy (SIMS) during all stages of cleaning and etching. More experimental details can be found in Refs. 6 and 7.

Although congruent lithium niobate has a roomtemperature absorption coefficient of less than $1 \mathrm{~cm}^{-1}$ at $351 \mathrm{~nm},{ }^{8}$ some absorption is still possible through the participation of defect levels in the energy gap. The defect levels will mainly be due to $\mathrm{Li}$ and $\mathrm{O}$ vacancies in the crystal. Electrons excited to or from these levels will quickly relax, heating the crystal lattice in the process. Because of the low thermal conductivity of lithium niobate, heat dissipation away from the laser spot will be low. Since the band gap of lithium niobate decreases rapidly with increasing temperature $^{8}$ and since we operate at a wavelength close to the band-gap energy, positive feedback will eventually enable band-to-band photon absorption.

The precise power and time needed to initiate the absorption process depends on the optical configuration and the
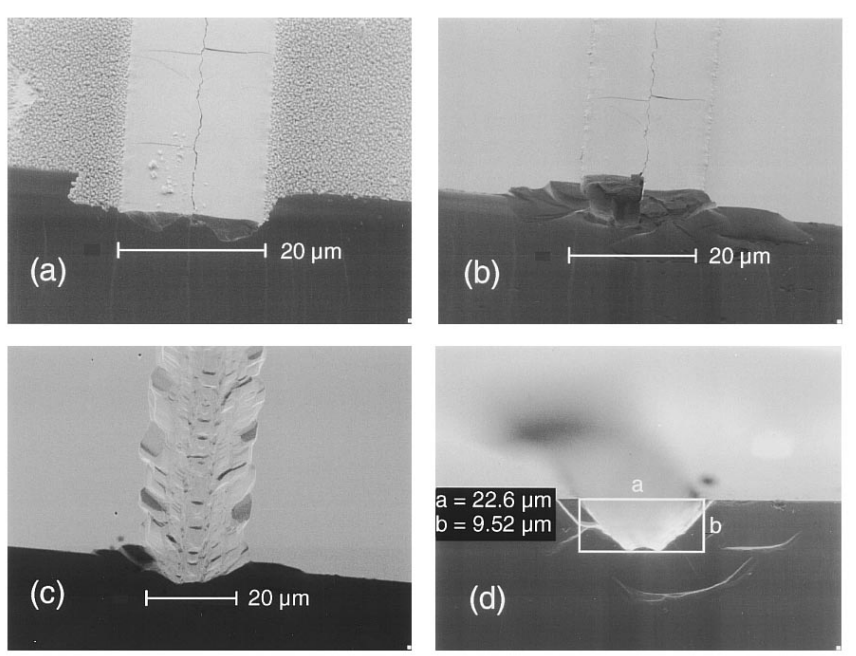

FIG. 1. $\mathrm{LiNbO}_{3}$ sample after laser processing. $300 \mathrm{~mW}, 100 \mathrm{~mm} / \mathrm{s}, 2 \omega=8$ $\mu \mathrm{m}$. (a) Before any cleaning, (b) after cleaning with ethanol, (c)(d) and after hot HF etch. 


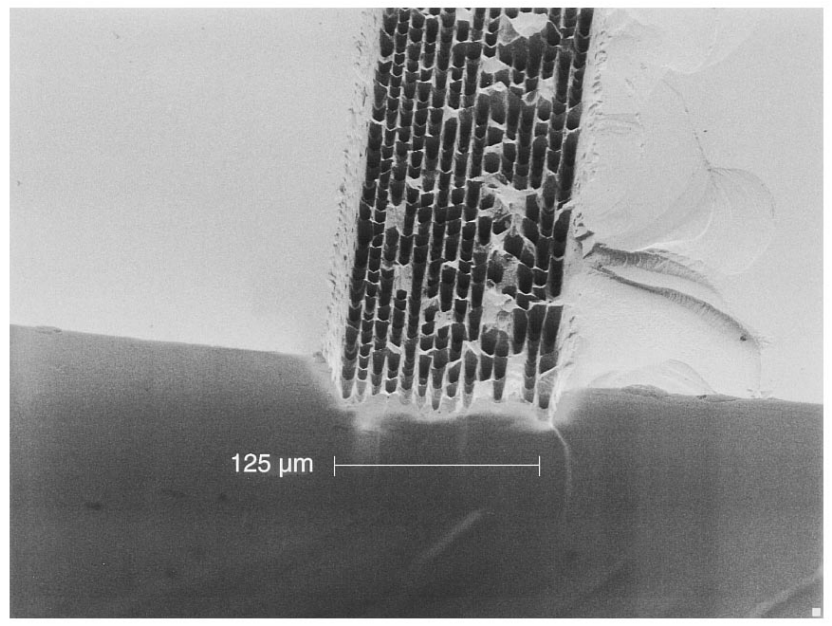

FIG. 2. Equidistant $(10 \mu \mathrm{m})$ parallel scans. $300 \mathrm{~mW}, 1 \mathrm{~mm} / \mathrm{s}, 2 \omega=8 \mu \mathrm{m}$

quality of the substrate, but focusing $\sim 500 \mathrm{~mW}$ of laser power on a $8 \mu \mathrm{m}$ spot for a few seconds can initiate absorption. This creates a damaged area with a much higher absorption coefficient than the original substrate. Using this area as a starting point, the laser spot can be scanned across the undamaged substrate at high speeds and at lower laser powers while maintaining the process. ${ }^{6}$ We explain this through heat dissipation in all directions away from the laser spot including the forward direction. In this way, the absorption coefficient of the substrate is increased before the laser spot travels across. The fact that the resulting trench depth depends on the scan speed of the laser $\operatorname{spot}^{6}$ suggests that the time constant for the process is in the millisecond range.

The process is a combination of ablation and transformation as can be seen in Fig. 1(a), which shows a SEM micrograph of a laser-processed sample before any cleaning. The figure shows a well-defined boundary between droplets of redeposited ablated material and an area of transformed material on the substrate surface. The redeposited material can easily be removed with ethanol [Fig. 1(b)], whereas the transformed material maintains a high degree of chemical resistivity. It can, however, be removed by $50 \%$ concentrated $\mathrm{HF}$ at $70^{\circ} \mathrm{C}$ in less than $1 \mathrm{~h}$, which leaves the unprocessed substrate intact as can be seen in Figs. 1(c) and 1(d). Figure 2 demonstrates that the process can be used for fast largearea removal of lithium niobate.

The samples were characterized by SIMS during all stages of cleaning and etching. Table I summarizes the count

TABLE I. SIMS element count ratios.

\begin{tabular}{lcccc}
\hline \hline & $\begin{array}{c}\text { Unprocessed. } \\
\text { Pure } \\
\text { material }\end{array}$ & $\begin{array}{c}\text { No cleaning. } \\
\text { Redeposited } \\
\text { material }\end{array}$ & $\begin{array}{c}\text { After ethanol. } \\
\text { Transformed } \\
\text { material }\end{array}$ & $\begin{array}{c}\text { After hot HF. } \\
\text { Remaining } \\
\text { material }\end{array}$ \\
\hline $\mathrm{Li} / \mathrm{Nb}$ & $1 / 4$ & $4 / 1$ & $1 / 33$ & $1 / 4$ \\
$\mathrm{O} / \mathrm{Nb}$ & $1 / 6$ & $2 / 3$ & $1 / 20$ & $1 / 5$ \\
\hline \hline
\end{tabular}

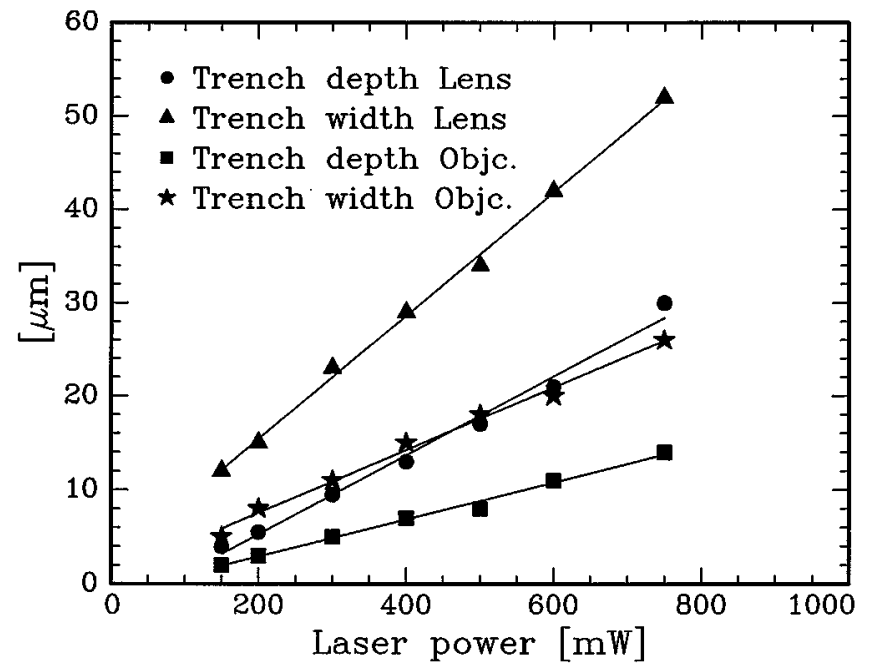

FIG. 3. Trench size vs laser power. $100 \mathrm{~mm} / \mathrm{s}$, lens: $2 \omega=8 \mu \mathrm{m}$, objc.: $2 \omega=1$ $\mu \mathrm{m}$.

ratios during the different stages of processing. The SIMS data show that the redeposited material is $\mathrm{Li}$ - and O-rich in contrast to the transformed material, which is heavily reduced in $\mathrm{Li}$ and $\mathrm{O}$. Also notable is that the remaining substrate maintains its original composition after treatment with hot HF.

In order to demonstrate the volumetric removal rates achievable with our system, we investigated the power regime $100-750 \mathrm{~mW}$ for a scan speed of $100 \mathrm{~mm} / \mathrm{s}$. Results are shown in Fig. 3 for two different optical configurations, ${ }^{6}$ for a reflective objective with a numerical aperture of 0.5 and for a singlet lens with a focal length of $80 \mathrm{~mm}$. The figure shows that the trench size scales linearly with power for both configurations. At $100 \mathrm{~mW}$ the process could not be maintained. Using the lens, $750 \mathrm{~mW}$ results in a corresponding volumetric rate of more than $10^{6} \mu \mathrm{m}^{3} / \mathrm{s}$.

In conclusion, we have demonstrated a sub-band-gap laser micromachining technique for lithium niobate. Using sub-band-gap photons enables one to utilize readily available and powerful cw Ar-ion lasers, thereby achieving volumetric removal rates orders of magnitude higher than previously reported in the literature. This opens the possibility of fast micromachining of complex piezoelectric structures as well as grooves for precision positioning of optical fibers in lithium niobate.

${ }^{1}$ EMIS Data Reviews Series No. 5, Properties of Lithium Niobate (INSPEC, London and New York, 1989).

${ }^{2}$ C. I. H. Ashby and P. J. Brannon, Appl. Phys. Lett. 49, 475 (1986).

${ }^{3}$ M. Eyett and D. Bäuerle, Appl. Phys. Lett. 51, 2054 (1987).

${ }^{4}$ K. W. Beeson, V. H. Houlding, R. Beach, and R. M. Osgood, Jr., J. Appl. Phys. 64, 835 (1988).

${ }^{5}$ K. W. Beeson and N. S. Clements, Mater. Res. Soc. Symp. Proc. 129, 321 (1989).

${ }^{6}$ F. K. Christensen and M. Müllenborn, IEEE Ultrason. Symp. Proc., 391 (1994).

${ }^{7}$ M. Müllenborn, H. Dirac, and J. W. Petersen, Appl. Surf. Sci. 86, 568 (1995).

${ }^{8}$ D. Redfield and W. J. Burke, J. Appl. Phys. 45, 4566 (1974). 